\title{
Sterile Feminine Hygiene Sanitary Napkin Dressing in the Management of Ludwig's Angina
}

\author{
${ }_{1}^{1}$ Pushkar Waknis, ${ }^{2}$ Sachin C Sarode, ${ }^{3}$ GSV Prasad, ${ }^{4}$ Gandhali Limaye, ${ }^{5}$ Gargi S Sarode
}

\section{ABSTRACT}

Dry environment plays a very important role in the healing of infections. Commercially available sanitary pads were sterilized individually using ethylene trioxide (ETO) for 24 hours and used as dressing material in 10 Ludwig's angina patients. When compared with conventional gauze dressing, it showed significantly less number of dressing changes. We recommend its use as an alternative absorbent wound material for head and neck infections.

Keywords: Dressing material, Ludwig's angina, Odontogenic infection, Sanitary napkin.

How to cite this article: Waknis P, Sarode SC, Prasad GSV, Limaye G, Sarode GS. Sterile Feminine Hygiene Sanitary Napkin Dressing in the Management of Ludwig's Angina. World J Dent 2015;6(4):239-240.

\section{Source of support: Nil}

Conflict of interest: None

\section{INTRODUCTION}

Dry environment plays a very important role in the healing of infections. Wet environment leads to repeated dressing, exposing the wound for contamination, risk of infection and increased length of hospital stay. One of the important factors that contribute to dryness is the dressing material. For this purpose, use of sterile feminine hygiene sanitary napkins (SFHSN) for wound dressing to absorb fluids and secretions have been reported..$^{1-4}$

\footnotetext{
${ }^{1}$ Professor and Consultant, ${ }^{2,3}$ Professor, ${ }^{4}$ Resident

${ }^{5}$ Associate Professor

${ }^{1}$ Department of Maxillofacial Surgery, Dr DY Patil Dental College and Hospital, Dr DY Patil Vidyapeeth, Ruby Hall Clinic, Pune Maharashtra, India

${ }^{2,5}$ Department of Oral Pathology and Microbiology, Dr DY Patil Dental College and Hospital, Dr DY Patil Vidyapeeth, Pune Maharashtra, India

${ }^{3}$ Department of Oral and Maxillofacial Surgery, Sharad Pawar Dental College and Hospital, Wardha, Maharashtra, India

${ }^{4}$ Department of Maxillofacial Surgery, Dr DY Patil Vidyapeeth Pune, Maharashtra, India

Corresponding Author: Sachin C Sarode, Professor, Department of Oral Pathology and Microbiology, Dr DY Patil Dental College and Hospital, Dr DY Patil Vidyapeeth, Sant-Tukaram Nagar, Pimpri Pune-411018, Maharashtra, India, Phone: +919922491465, e-mail: drsachinsarode@gmail.com
}

\section{LITERATURE REVIEW}

Smoot $\mathrm{EC}^{1}$ is the first to use SFHSN as an alternative dressing material. Demir A et $\mathrm{al}^{3}$ used SFHSN for dressing of grafted skin and donor areas. Shetty $\mathrm{VD}^{4}$ reported the use of SFHSN for dressings in total hip and knee replacement wounds. It facilitated the management of the joint replacement wounds very effectively. This method is economical and reduces the number of man hours. There are no reports of use of SFHSN in head and neck infections in the literature till date. Hence, attempt has been made to study the use of SFHSN for dressing in Ludwig's angina.

\section{TECHNIQUE}

Commercially available sanitary pads were sterilized individually using ethylene trioxide (ETO) for 24 hours. These pads were directly applied to the wound and affixed to the skin using large Tegaderm transparent dressings/micropore dressing tape $(3 \mathrm{M}, \mathrm{St}$ Paul, $\mathrm{MN})$ in 10 Ludwig's angina patients. The length of the napkin was adjusted by cutting it to the appropriate dimensions so that it was long enough to cover the entire neck from one side of the angle of mandible to the other (Fig. 1). When the neck wound was in the granulation stage and no longer required placement of roller gauze for evacuation of pus from the deep neck spaces, SFHSN dressing was applied. Then the results were compared with the outcome of conventional gauze dressing (Table 1). The confounding factors like age, sex and body mass indes (BMI) were kept constant as far as possible. The results showed that

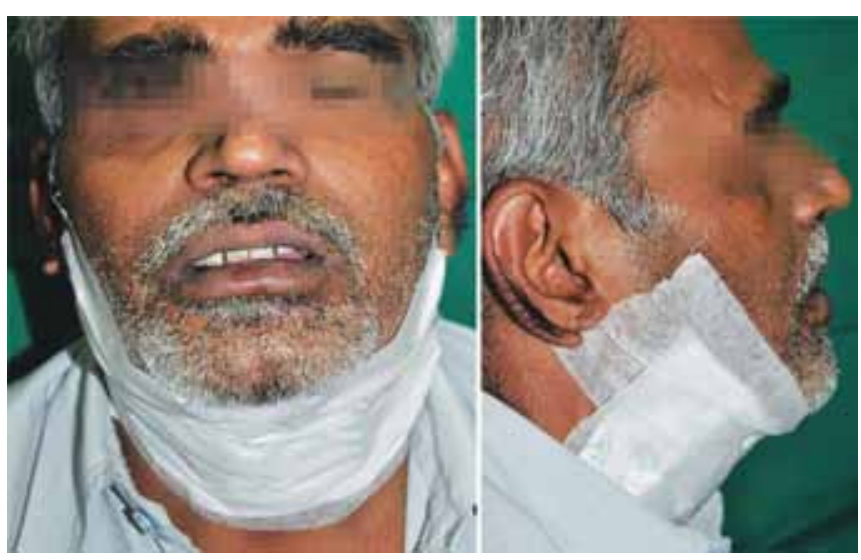

Fig. 1: Sterile sanitary napkin covering the entire neck from one side of the angle of mandible to the other 
Table 1: Comparison between standard gauze and sanitary pad dressing groups

\begin{tabular}{llll}
\hline & $\begin{array}{l}\text { Standard gauze } \\
\text { dressing group }\end{array}$ & $\begin{array}{l}\text { Sterile sanitary } \\
\text { pad dressing } \\
\text { group }\end{array}$ & p-value \\
\hline Parameters & 10 & 10 & \\
\hline $\begin{array}{l}\text { Number } \\
\text { Male:female }\end{array}$ & $2.33: 1$ & $2.33: 1$ & \\
$\begin{array}{l}\text { Mean age } \\
\text { (years) }\end{array}$ & $45.7 \pm 3.33$ & $47.9 \pm 4.99$ & 0.2621 \\
$\begin{array}{l}\text { Mean BMI } \\
\begin{array}{l}\text { Mean number } \\
\text { of dressing } \\
\text { changes }\end{array}\end{array}$ & $29.12 \pm 2.62$ & $29.38 \pm 2.57$ & 0.829 \\
\hline
\end{tabular}

the mean number of dressing changes required was reduced significantly in SFHSN dressing as compared to conventional gauze dressing.

\section{DISCUSSION}

Sterile feminine hygiene sanitary napkins are readily available in different sizes in stores and can be easily sterilized with ethylene oxide. These materials are sufficiently absorbent for fluids and secretions. With the use of SFHSN, it is possible to reduce the number of dressings significantly in head and neck infection. In patients with odontogenic infections like Ludwig's angina we need the patient to come for dressing to the clinic. Most patients with facial abscess are in poor physical state and it is cumbersome to come every day to change the dressing. Also, this can be easily done by the patients' caretakers at home, and thus is economical also. The product is easily available in every household and just needed to be given to the patient in sterile form. We recommend its use as an alternative absorbent wound material for head and neck infections. We also believe that such form of dressing is more important in medically compromised patients especially immunocompromised ones, where chances of re-infection and/or exacerbation are more. The research is being carried out to study the use of SFHSN in such patients.

\section{REFERENCES}

1. Smoot EC. Alternative wound dressings. Plast Reconstr Surg 1998;102(1):268.

2. Varon J. Feminine hygiene sanitary napkins for wound dressings. Plast Reconstr Surg 1999;103(5):1543.

3. Demir A, Eroğlu L. The use of sterilized feminine hygiene sanitary napkins for dressing of skin-grafted and donor areas. Plast Reconstr Surg 2003;111(7):2475.

4. Shetty VD. Dry wounds matter: the use of occlusive sterile sanitary napkin dressing in hip and knee replacement wounds. Int Wound J 2010;7(5):428-429. 